Premiere Educandum: Jurnal Pendidikan Dasar dan Pembelajaran

Volume 8(2) 206 - 212 Desember 2018

Copyright @2018 Universitas PGRI Madiun

ISSN: 2088-5350 (Print) / ISSN: 2528-5173 (Online)

Available at: http://e-journal.unipma.ac.id/index.php/PE

Doi: $10.25273 /$ pe.v8i2.3207

\title{
Validasi modul pembelajaran: Materi dan desain tematik berbasis PPK
}

\author{
Denna Delawanti Chrisyarani ${ }^{1}$, Arnelia Dwi Yasa ${ }^{2}$ \\ ${ }^{1,2}$ Fakultas Ilmu Pendidikan, Universitas Kanjuruhan Malang \\ 1 email: dennadelawanti@unikama.ac.id \\ 2email: arnelia@unikama.ac.id
}

\begin{abstract}
This study aims to develop a valid PPK-based thematic module based product. The modules that will be developed have never been found on the surface, because there are PPK habituation activities and thematic material management with PPK. Strengthening character in PPK is religious, nationalist, independent, mutual cooperation, and integrity. This study uses the design research development of Borg and Gall. The module development procedures, namely: (1) research / study introduction and data collection, (2) planning, (3) draft development product, (4) the initial field trial or in this study is a test validation by experts, (5) revising the results of the initial field trials, (6) field trials the main or in this study is a small scale trial, (7) revise the product the results of the main field test, (8) field implementation test or in this study is a field / class trial, (9) final product revision The instrument used is a questionnaire. The results of this study are to determine validity. Material validation was obtained by a percentage of $95 \%$ and in terms of design $93 \%$, in a very valid category.
\end{abstract}

Keywords: Thematic modules, characters, PPK

\begin{abstract}
Abstrak
Penelitian ini bertujuan untuk menghasilkan produk pengembangan berupa modul tematik berbasis PPK yang valid. Modul yang akan dikembangkan belum pernah ditemui di lapangan, karena terdapat kegiatan pembiasaan PPK dan pengintegrasian materi tematik dengan PPK. Karakter yang diperkuat pada PPK adalah religius, nasionalis, mandiri, gotong royong, dan integritas. Adapun prosedur pengembangan modul, yaitu: (1) penelitian/studi pendahuluan dan pengumpulan data, (2) perencanaan, (3) pengembangan draf produk, (4) uji coba lapangan awal atau dalam penelitian ini merupakan uji validasi oleh ahli, (5) merevisi hasil uji coba lapangan awal, (6) uji coba lapangan utama atau dalam penelitian ini adalah uji coba skala kecil, (7) merevisi produk hasil uji lapangan utama, (8) uji pelaksanaan lapangan atau dalam penelitian ini adalah uji coba lapangan/kelas, (9) revisi produk akhir. Instrumen yang digunakan adalah angket. Hasil dari penelitian ini untuk mengetahui kevalidan dari segi materi dan desain. Segi validasi materi diperoleh prosentase $95 \%$ dan dari segi desain $93 \%$, dalam kategori sangat valid.
\end{abstract}

Kata Kunci: Modul tematik, karakter, PPK

\section{A. PENDAHULUAN}

Siswa sekolah dasar memiliki rentang usia 6-12 tahun. Periode ini dimulai dengan masuknya anak ke lingkungan sekolah, yang memiliki dampak dalam perkembangan dan hubungan anak dengan orang lain. Lingkungan, interaksi yang dialami dan diterimanya akan mempengaruhi pertumbuhan dan perkembangan anak, 
sehingga lambat laun anak menjadi seorang yang lebih dewasa (Gunarsa, 2008).

Berbagai faktor yang mempengaruhi proses perkembangan dan interaksi yang dilakukannya juga mengarah pada pembentukan karakter. Karakter terbentuk dari tiga macam bagian yang saling berkaitan: pengetahuan moral, perasaan moral, dan perilaku moral (Lickona, 2013). Dalam pembentukan inilah dibutuhkan suatu kesadaran akan nilai sehingga menjadi sebuah kebiasaan. Pembiasaan akan nilai-nilai baik yang harus ditanamkan sedini mungkin, bertolak dari permasalahan dan krisis moral yang sedang bergema. Untuk itu seluruh lingkungan sekolah harus dapat mendukung perkembangan tersebut.

Pendidikan karakter sudah pernah diluncurkan sebagai gerakan nasional pada 2010 (Judiani, 2010). Namun, gema gerakan pendidikan karakter ini belum cukup kuat. Pendidikan karakter perlu diperkuat kembali melalui program nasional Penguatan Pendidikan Karakter (PPK). PPK adalah program pendidikan di sekolah untuk memperkuat karakteristik siswa melalui harmonisasi olah hati, olah rasa, olah pikir, dan olahraga dengan dukungan pelibatan publik dan kerjasama antara sekolah, keluarga, dan masyarakat yang merupakan bagian dari Gerakan Nasional Revolusi Mental (GNRM) (Depdiknas, 2017). Menurut Depdiknas (2017) urgensi PPK dalah (1) pembangunan SDM merupakan pondasi pembangunan bangsa. (2) keterampilan abad 21 yang dibutuhkan siswa: kualitas karakter, literasi dasar, dan kompetensi 4C, guna mewujudkan keunggulan bersaing Generasi Emas 2045. (3) kecenderungan kondisi degradasi moralitas, etika, dan budi pekerti. Urgensi PPK inilah yang menjadi tolak ukur keberhasilan pembelajaran dari segi kualitas karakter, yang kemudian dijabarkan dalam pembelajaran tematik di SD.

$$
\text { Pembelajaran }
$$

tematik merupakan pembelajaran yang diterapkan dalam kurikulum 2013 (Sari \& Syamsi, 2015). Pembelajaran tematik adalah pembelajaran yang dirancang berdasarkan tema-tema tertentu yang dalam pembahasannya tema itu ditinjau dari berbagai mata pelajaran (Majid, 2014). Tematik adalah inti dari seluruh muatan pembelajaran yang mendorong siswa untuk memunculkan rasa ingin tahu dengan interaksinya tentang lingkungan di sekitar mereka (Akbar \& Sutama, 2010). Pembelajaran tematik mengarahkan guru agar lebih kreatif dan inovatif sehingga dapat menghasilkan pembelajaran yang utuh (Estuwardani \& Mustadi, 2015). Pengembangan tema pada pembelajaran tematik Kurikulum 2013 bertujuan agar proses pendidikan dapat menghasilkan insan Indonesia yang produktif, kreatif, inovatif, dan afektif melalui penguatan sikap dan pengetahuan yang terintegrasi.

Berdasarkan analisis bahan ajar tematik yang diterapkan di kelas IV Kota Malang, ditemukan bahwa bahan ajar tematik kurang bermuatan karakter. Bahan ajar berisi konsep dan kegiatan yang berhubungan dengan 
pengusaan konsep siswa terhadap tema yang dipelajari. Integrasi nilai karakter dalam mata pelajaran masih kurang dan aplikasi nilai-nilai karakter pada proses pembelajaran kurang jelas karakter yang dimunculkan pada pembelajaran (Fatmawati, Pratiwi, \& Erviana, 2018). Penekanan pada Lima nilai karakter (religius, nasionalis, mandiri, gotong royong, integritas) perlu ditambahkan. Ditinjau dari sisi karakteristik anak dan pembelajaran tematik yang diuraikan, maka pengembangan modul tematik berbasis PPK penting untuk dilakukan.

Pengembangan modul telah banyak dilakukan dan dipelajari dalam berbagai bidang. Beberapa penelitian sebelumnya mengembangkan modul tematik (Aisyi et al., 2013; Amir \& Kusuma, 2018; Fatmawati et al., 2018; Mudiono, Akbar, Dwi Yasa, \& Delawanti Chrisyarani, 2017; Troseth \& Strouse, 2017). Melakukan validasi modul tematik (Chrisyarani \& Akbar, 2017; Łakuta, 2018; Peeters \& Martin, 2017). Penerapan modul dalam pembelajaran (Nilasari, Try Djatmika, \& Santoso, 2016). Uji kelayakan modul ditinjau dari segi materi tematik mengenai PPK dan dari segi desain.

Tujuan penelitian ini, secara umum untuk menghasilkan modul tematik berbasis PPK yang valid, menarik dan praktis; secara khusus untuk mendeskripsikan kevalidan modul tematik berbasis PPK.

\section{B. METODE PENELITIAN}

Pengembangan modul tematik berbasis PPK menggunakan model Borg \& Gall. Adapun prosedur pengembangan modul, yaitu: penelitian/studi

pendahuluan dan pengumpulan data, (2) perencanaan, (3) pengembangan draf produk, (4) uji coba lapangan awal atau dalam penelitian ini merupakan uji validasi oleh ahli, (5) merevisi hasil uji coba lapangan awal, (6) uji coba lapangan utama atau dalam penelitian ini adalah uji coba skala kecil, (7) merevisi produk hasil uji lapangan utama, (8) uji pelaksanaan lapangan atau dalam penelitian ini adalah uji coba lapangan/kelas, (9) revisi produk akhir. Secara khusus, penelitian pada artikel ini berhenti pada tahap 4, yaitu uji coba lapangan awal atau dalam penelitian ini merupakan uji validasi oleh ahli. Mendeskripsikan mengenai hasil validasi ahli, hasil uji kemenarikan dan kepraktisan. Bahan ajar yang berkualitas, jika memenuhi aspek-aspek: validitas (validity), kepraktisan (practicality), dan keefektifan (effectiness) (Hobri, 2010) - Pada penelitian dan pengembangan modul ini, peneliti menambahkan aspek kemenarikan, untuk mengetahui respon dari siswa tentang modul yang digunakan.

Subjek uji coba dalam penelitian ini adalah ahli materi, ahli media, guru, dan siswa. instrumen pengumpulan data yang digunakan adalah angket. Teknik analisis yang digunakan adalah analisis data kualitatif dan analisis data kuantitatif. Analisis data kualitatif diperoleh dari masukan, saran dari validator ahli isi/ materi, ahli media. Analisis data kuantitatif diperoleh dari skor angket.

Data yang diperoleh dari angket validasi para ahli dianalisis dengan 
persentase yang menggunakan rumus.

Rumus untuk mengolah data hasil validasi kepada para ahli diadaptasi dengan modifikasi dari (Akbar, S., Sriwiyana, 2012) adalah sebagai berikut:

$$
\begin{array}{ll}
V m=\frac{T S e}{T \operatorname{sh}} \times 100 \% & V d=\frac{T S e}{T \operatorname{sh}} \times 100 \% \\
V t=\frac{V m+V d}{2}=\cdots \% &
\end{array}
$$

Gambar 1. Rumus Pengolahan data Validasi

Keterangan:

$\mathrm{Vm}=$ Validitas ahli materi/isi

$\mathrm{Vd} \quad=$ Validitas ahli desain

TSe = Total Skor Empirik yang

dicapai (berdasarkan penilaian ahli)

TSh = Total skor yang diharapkan

$\mathrm{Vt}=$ Validasi total/gabungan

$100 \%=$ konstanta

Tabel 1 Kriteria Kevalidan Modul Tematik

\begin{tabular}{|c|c|c|c|c|}
\hline $\begin{array}{l}\mathrm{N} \\
\mathrm{o} .\end{array}$ & $\begin{array}{l}\text { Skor } \\
\text { Kemen } \\
\text { arikan }\end{array}$ & $\begin{array}{l}\text { Tingkat } \\
\text { Kemenar } \\
\text { ikan }\end{array}$ & $\begin{array}{l}\text { Tingkat } \\
\text { keprakt } \\
\text { isan }\end{array}$ & $\begin{array}{l}\text { Tingkat } \\
\text { kevalid } \\
\text { an }\end{array}$ \\
\hline 1. & $\begin{array}{l}86 \%- \\
100 \%\end{array}$ & $\begin{array}{l}\text { Sangat } \\
\text { menarik, } \\
\text { tidak } \\
\text { perlu } \\
\text { revisi }\end{array}$ & $\begin{array}{l}\text { Keprak } \\
\text { tisan } \\
\text { sangat } \\
\text { baik, } \\
\text { tidak } \\
\text { perlu } \\
\text { revisi }\end{array}$ & $\begin{array}{l}\text { Sangat } \\
\text { Valid } \\
\text { (dapat } \\
\text { diguna } \\
\text { kan } \\
\text { tanpa } \\
\text { revisi) }\end{array}$ \\
\hline 2. & $\begin{array}{l}70 \%- \\
85 \%\end{array}$ & $\begin{array}{l}\text { cukup } \\
\text { menarik, } \\
\text { tidak } \\
\text { perlu } \\
\text { revisi }\end{array}$ & $\begin{array}{l}\text { Keprak } \\
\text { tisan } \\
\text { baik, } \\
\text { tidak } \\
\text { perlu } \\
\text { revisi }\end{array}$ & $\begin{array}{l}\text { cukup } \\
\text { Valid } \\
\text { (dapat } \\
\text { diguna } \\
\text { kan } \\
\text { dengan } \\
\text { revisi) }\end{array}$ \\
\hline 3. & $\begin{array}{l}60 \%- \\
69 \%\end{array}$ & $\begin{array}{l}\text { kurang } \\
\text { menarik, } \\
\text { perlu } \\
\text { revisi } \\
\text { kecil }\end{array}$ & $\begin{array}{l}\text { Keprak } \\
\text { tisan } \\
\text { cukup, } \\
\text { perlu } \\
\text { revisi } \\
\text { kecil }\end{array}$ & $\begin{array}{l}\text { tidak } \\
\text { Valid } \\
\text { (tidak } \\
\text { dapat } \\
\text { diguna } \\
\text { kan) }\end{array}$ \\
\hline 4. & $\begin{array}{l}0 \%- \\
59 \%\end{array}$ & $\begin{array}{l}\text { tidak } \\
\text { menarik, } \\
\text { revisi } \\
\text { total }\end{array}$ & $\begin{array}{l}\text { Keprak } \\
\text { tisan } \\
\text { kurang, } \\
\text { revisi } \\
\text { total }\end{array}$ & $\begin{array}{l}\text { sangat } \\
\text { tidak } \\
\text { valid }\end{array}$ \\
\hline
\end{tabular}
Berbasis PPK
(Sumber: diadaptasi dari (Akbar, S., Sriwiyana, 2012))

\section{HASIL DAN PEMBAHASAN}

Data validasi, uji kemenarikan dan kepraktisan modul tematik berbasis MI diketahui melalui lembar validasi berupa angket. Data tersebut dikumpulkan untuk mengetahui tingkat kevalidan dan hasil uji coba skala kecil. Produk divalidasikan kepada dua orang ahli, yaitu ahli materi dan media.

Validasi ahli materi diperlukan sebagai evaluator terhadap materi serta bahasa yang sudah dikembangkan oleh peneliti. Data yang diperoleh berupa data kuantitatif dan kualitatif melalui angket yang diberikan peneliti kepada ahli materi.

Hasil validasi oleh ahli materi menunjukkan bahwa rata-rata persentase kevalidan modul siswa sebesar $95 \%$ yang berarti modul sangat valid dan dapat digunakan tanpa revisi dari segi materi. Meski demikian, peneliti tetap melakukan revisi dengan memerhatikan saran yang diberikan oleh validator. Saran perbaikan dari hasil validasi ahli materi yaitu perlu ditambahkan refleksi dalam kegiatan pembelajaran dan sudah direvisi.

Validasi media diperlukan sebagai evaluasi terhadap media modul yang dikembangkan oleh peneliti. Data yang diperoleh berupa data kuantitatif dan kualitatif melalui angket yang diberikan peneliti kepada ahli media pembelajaran.

Hasil validasi oleh ahli media menunjukkan bahwa rata-rata persentase kevalidan modul siswa 
sebesar $94 \%$ yang berarti modul siswa valid. Peneliti juga memerhatikan saran dari validator untuk perbaikan produk selanjutnya. Saran perbaikan dari hasil validasi ahli media yaitu cover harap dicetak dengan kertas foto dan sudah dilakukan revisi.

Berdasarkan paparan data kevalidan produk ditinjau dari isi dan penyajian modul oleh para ahli, didapatkan rekapitulasi validasi total atau gabungan pada tabel 3 berikut ini.

Tabel 2. Rekapitulasi Data Validasi Total Modul Tematik Berbasis PPK

\begin{tabular}{ll}
\hline Aspek & Validator \\
\hline Materi & $95 \%$ \\
\hline Media & $93 \%$ \\
\hline Jumlah & 188 \\
\hline Rata-rata & 94 \\
\hline
\end{tabular}

Data validasi total modul siswa memperoleh persentasi sebesar $94 \%$ dengan kriteria sangat valid.

Berdasarkan data hasil validasi yang dilakukan ahli, hasil uji kemenarikan oleh siswa dan uji kepraktisan oleh guru pada modul diketahui bahwa modul tematik berbasis PPK yang dikembangkan sudah sesuai dengan teori dan dapat digunakan dalam pembelajaran. Presentase kevalidan produk sebesar 94\% dari skor maksimal yang diharapkan, dengan kriteria sangat valid.

Dari segi materi, tingkat kevalidan modul ini sebesar 95\% dengan kriteria sangat valid. Modul ini memiliki kelebihan dalam hal rancangan materi berupa pembelajaran tematik yang dipadukan dengan PPK, untuk menanamkan nilai-nilai dalam diri siswa. Karakter berkaitan dengan interaksi atau tindakan yang dilakukan sesorang. Karakter meliputi nilai-nilai moral, sikap, dan perilaku (Rokhman, Hum, Syaifudin, \& Yuliati, 2014). Berdasarkan hal tersebut, Konsep pendidikan karakter tidak diajarkan tetapi dimasukkan dalam contoh aplikasi nilai-nilai untuk pembentukan kebiasaan (Fahmy, Bachtiar, Rahim, \& Malik, 2015); Mendidik karakter dengan melihat kondisi atau permasalahan dari siswa, materi pembelajaran, evaluasi pembelajaran.

Bahasa dituliskan dalam modul disesuaikan dengan tingkat pemahaman siswa kelas IV yang berada pada tahap operasional konkrit. Bahasa yang digunakan dalam modul ini adalah bahasa Indonesia ragam semi formal yang bersifat komunikatif. Salah satu indikator kelayakan bahasa adalah pemakaian bahasa yang komunikatif (Muslich, 2010). Artinya, bahasa dalam bahan ajar mengutamakan komunikasi antara penulis dan pembaca.

Ditinjau dari segi media, tingkat kevalidan modul ini sebesar 93\%, dengan kritria sangat valid. Tingginya tingkat kevalidan dari aspek media, dikarenakan modul ini didesain dengan warna-warna yang cerah, tata letak penulisan yang menarik dan gambar yang mendukung materi (Mudiono et al., 2017; Yasa, Chrisyarani, Akbar, \& Mudiono, 2016). Pembelajaran akan berjalan dengan maksimal jika pesan/materi disampaikan secara jelas, runtut, dan menarik. 


\section{SIMPULAN}

Penelitian ini menghasilkan modul tematik berbasis PPK yang valid dengan presentase total sebesar 95\%. Validasi materi dengan presentase sebesar 95\%. Validasi media dengan presentase sebesar $93 \%$. Modul tematik berbasis PPK layak digunakan sebagai bahan ajar untuk membantu siswa dan guru pada proses pembelajaran. Diharapkan setelah melakukan validasi dan mendapatkan prosentase yang baik, peneliti dapat melanjutkan melakukan uji coba produk kepada siswa dan guru untuk mengetahui kemenarikan dan kepraktisan.

\section{DAFTAR RUJUKAN}

Aisyi, F. K., Elvyanti, S., Gunawan, T., Mulyana, E., Studi, P., \& Teknik, P. (2013). Pengembangan Bahan Ajar Tik Smp Mengacu, IX(2), 117-128.

Akbar, S., Sriwiyana, H. (2012). Pengembangan Kurikulum dan Pembelajaran Ilmu Pengetahuan Sosial. Yogyakarta: Cipta Media.

Akbar, S., \& Sutama, I. W. (2010). Pengembangan Model Pembelajaran Tematik untuk Kelas 1 dan Kelas 2 Sekolah Dasar Sa'dun, 17(April), 32-40.

Amir, M. F., \& Kusuma, M. D. (2018). Pengembangan Perangkat Pembelajaran Berbasis Masalah Kontekstual Untuk Meningkatkan Kemampuan Metakognisi Siswa Sekolah Dasar. Journal of Medives, 2(1), 117-128. Retrieved from http://e-journal.ikip-

veteran.ac.id/index.php/matematika/ article/view/538

Chrisyarani, D. D., \& Akbar, S. (2017). Modul komik tematik berbasis. Sekolah Dasar: Kajian Teori Dan Praktik Pendidikan, Tahun $26 \mathrm{~N}$, 175-181. https://doi.org/http://dx.doi.org/10.1 7977/um009v26i22017p175

Depdiknas. (2017). Panduan Pengembangan Bahan Ajar. Jakarta.

Estuwardani, N. A., \& Mustadi, A. (2015). Pengembangan Bahan Ajar Modul Tematik-Terintegratif dalam Peningkatan Karakter Peserta Didik Kelas 1 Sekolah Dasar. Jurnal Pendidikan Karakter, 5(2), 157-172. Retrieved from https://journal.uny.ac.id/index.php/jp $\mathrm{ka} /$ article/view/8620/7113

Fahmy, R., Bachtiar, N., Rahim, R., \& Malik, M. (2015). Measuring Student Perceptions to Personal Characters Building in Education: An Indonesian Case in Implementing New Curriculum in High School. Procedia - Social and Behavioral Sciences, 211, 851-858. https://doi.org/10.1016/j.sbspro.2015 .11 .112

Fatmawati, L., Pratiwi, R. D., \& Erviana, V. Y. (2018). Pengembangan Modul Pendidikan Multikultural Berbasis Karakter Cinta Tanah Air dan Nasionalis pada Pembelajaran Tematik. Scholaria: Jurnal Pendidikan Dan Kebudayaan, 8(1), 80-92.

Gunarsa, S. D. (2008). Psikologi Anak: Psikologi Perkembangan Anak dan Remaja. Jakarta: PT BPK Gunung Mulia.

Hobri. (2010). Metodologi Penelitian Pengembangan (Aplikasi Pada Penelitian Pendidikan Matematika). Jember: Pena Salsabila.

Judiani, S. (2010). Implementasi Pendidikan Karakter di Sekolah Dasar Melalui Penguatan Pelaksanaan Kurikulum. Jurnal Pendidikan Dan Kebudayaan, 16(April), 280-289.

Łakuta, P. (2018). Social anxiety questionnaire (SAQ): Development and preliminary validation. Journal of Affective Disorders, 238, 233243. 
https://doi.org/10.1016/j.jad.2018.05 .036 .

Lickona, T. (2013). Educating For Character. Jakarta: Bumi Aksara.

Majid, A. (2014). Pembelajaran Tematik Terpadu. Bandung: PT. Remaja Rosdakarya.

Mudiono, A., Akbar, S., Dwi Yasa, A., \& Delawanti Chrisyarani, D. (2017). Developing Multiple IntelligencesBased Thematic Comic Module. Pancaran Pendidikan, 6(4), 115124.

https://doi.org/10.25037/pancaran.v6 i4.111.

Muslich, M. (2010). Text Book Writing, Dasar-dasar Pemahaman, Penulisan dan Pemakaian Buku Teks. Yogyakarta: Arruzz Media.

Nilasari, E., Try Djatmika, E., \& Santoso, A. (2016). Pengaruh penggunaan modul pembelajaran kontekstual terhadap hasil belajar siswa kelas V sekolah dasar. Juenal Pendidikan, 1(7), 1399-1404.

Peeters, M. J., \& Martin, B. A. (2017). Validation of learning assessments: A primer. Currents in Pharmacy Teaching and Learning, 9(5), 925933.

https://doi.org/10.1016/j.cpt1.2017.0
6.001.

Rokhman, F., Hum, M., Syaifudin, A., \& Yuliati. (2014). Character Education for Golden Generation 2045 (National Character Building for Indonesian Golden Years). Procedia - Social and Behavioral Sciences, 141, 1161-1165. https://doi.org/10.1016/j.sbspro.2014 .05.197.

Sari, I. P., \& Syamsi, K. (2015). Pengembangan Buku Pelajaran Tematik-Integratif Berbasis Nilai Karakter Disiplin dan Tanggung Jawab Di Sekolah Dasar. Jurnal Prima Edukasia, 3(1), 73-83. https://doi.org/10.21831/JPE.V3I1.4 070.

Troseth, G. L., \& Strouse, G. A. (2017). Designing and using digital books for learning: The informative case of young children and video. International Journal of ChildComputer Interaction, 12, 3-7. https://doi.org/10.1016/j.ijcci.2016.1 2.002 .

Yasa, A. D., Chrisyarani, D. D., Akbar, S., \& Mudiono, A. (2016). A framework development of thematic comic module based multiple intelegence, 5-10. 